\title{
Produção científica sobre docência em saúde no Brasil
}

\author{
Scientific production on health teaching in Brazil
}

Vinício Oliveira da Silva1, Isabela Cardoso de Matos Pinto ${ }^{2}$

DOI: 10.1590/0103-11042019S112

RESUMO O objetivo deste artigo foi analisar a produção científica sobre docência em saúde no Brasil, visando identificar os principais temas de investigação, abordagens e as possíveis lacunas do conhecimento. Realizou-se um estudo de síntese a partir de artigos publicados sobre a temática. Foram considerados estudos nacionais, com texto em língua portuguesa, publicados até o ano de 2017 no SciELO e na Lilacs. Foram analisados, na íntegra, 99 estudos, identificando pontos de convergência entre os assuntos tratados, sendo extraídas/definidas as seguintes categorias: Prática docente; Formação docente; Perfil docente; Identidade docente; Trajetória docente e Saúde do docente. Os anos que tiveram maior concentração de publicações foram 2011 e 2016 com, respectivamente, 13,13\%; e 2017 com 11,11\%. A distribuição quantitativa por tipo de estudo demonstra que $71,8 \%$ deles têm base empírica. A região Sudeste foi a que apresentou maior concentração (55,55\%), seguida da região Sul (18,18\%) e da região Nordeste (17,17\%). No que se refere às categorias temáticas, nos estudos, houve predominância da Prática docente (36,3\%), seguida de Formação docente (31,3\%) e Saúde do docente (18,2\%). A temática da docência em saúde apresenta inúmeras lacunas, reafirmando a necessidade de investimentos em pesquisas que tragam soluções para os desafios da educação na saúde na contemporaneidade.

PALAVRAS-CHAVE Docentes. Educação superior. Pessoal de saúde. Capacitação profissional. Recursos humanos em saúde.

ABSTRACT The aim of this article is to analyze the scientific production on health teaching in Brazil, seeking to identify the main research themes, approaches, and possible knowledge gaps. A synthesis study was carried out from published articles on the subject. We considered national studies, with text in Portuguese, published until 2017 in SciELO and Lilacs. A total of 99 studies were analyzed, identifying points of convergence between the subjects addressed, being the following categories extracted/defined: Teaching practice; Teacher training; Teacher profile; Teaching identity; Teacher trajectory and Teacher's health. The years that had the highest concentration of publications were 2011 (13.3\%), 2016 (13.13\%) and 2017 (11.11\%). The quantitative distribution by type of study shows that $71.8 \%$ have an empirical basis. The Southeast region had the highest concentration (55.55\%), followed by the South region (18.18\%) and the Northeast region (17.17\%).

1 Universidade Federal do Paraná (UFPR) - Matinhos (PR), Brasil. viniciooliveira@ufpr.br

2 Universidade Federal da Bahia (UFBA), Instituto de Saúde Coletiva (ISC) Salvador (BA), Brasil. In terms of thematic categories, there was a predominance of teaching practice (36.3\%), followed by teacher training (31.3\%) and teacher's health (18.2\%). The theme of teaching in health presents numerous gaps, reaffirming the need for investments in research that bring solutions to the challenges of health education in the contemporary world.

KEYWORDS Faculty. Education, higher. Health personnel. Professional training. Health manpower. 


\section{Introdução}

Nas duas últimas décadas, o ensino em saúde vem passando por transformações decorrentes da busca de modelos de formação que deem conta das necessidades sociais e que sejam coerentes com as mudanças no mundo do trabalho e com as políticas de saúde vigentes. Nesse contexto, é visível a inserção de novas tecnologias na produção do conhecimento que, consequentemente, revolucionam a disponibilidade e rapidez da informação. Esse cenário leva a refletir sobre a dinâmica do ensino, sobre as práticas pedagógicas, sobre o papel do professor na formação dos profissionais e sobre o perfil adequado à realidade em que estão inseridos ${ }^{1-3}$.

Com a implementação do Sistema Único de Saúde (SUS) no Brasil, a partir da década de 1990, ganhou destaque a reconfiguração de novas práticas de saúde na perspectiva de reorientação do modelo de atenção hegemônico e de superação dos desafios enfrentados pelos modelos de formação e qualificação profissional no campo da saúde. Esses processos vêm passando por inovações educacionais por meio de um conjunto de iniciativas que vivem a tensão entre o lugar da ruptura em direção a novos arranjos, as novas práticas de saúde e as novas interações entre campos de conhecimentos diversos, com sua tradicional ênfase em processos normalizadores e disciplinadores 4 .

No País, ao longo dos últimos 20 anos, observa-se uma reforma da educação superior aliada a uma política de expansão do ensino, adotando-se os princípios da diversificação e da diferenciação como novo ideário das políticas de ensino superior, bem como a disseminação de instituições voltadas apenas para o ensino, dissociado de pesquisa e extensão. Consequentemente, observa-se o aumento da produção de conhecimento, acompanhada de uma maior exigência na produção do trabalho docente, sobretudo no crescimento de publicações científicas. As universidades, portanto, estão situadas no centro do processo de produção da ciência, tecnologia e inovação, o que tem por consequência a transformação qualitativa do trabalho do professor ${ }^{5,6}$.

Nesse sentido, as mudanças na formação profissional em saúde exigem diálogo com as propostas pedagógicas e requerem que o docente estruture cenários de aprendizagem que sejam significativos e problematizadores da prática profissional. Esse contexto traz reflexões sobre a relação entre prática e formação docente, constituindo-se como importante desafio para o ensino superior em saúde, o qual se desenvolve em um panorama acadêmico marcado pela valorização da pesquisa em detrimento dos saberes pedagógicos ${ }^{7}$.

Nessa perspectiva, se a universidade e o sistema educacional vêm passando por reformas, com o intuito de dar conta da complexidade que caracteriza a saúde como processo social, a prática docente se caracteriza como potencial para transpor modelos educativos conservadores. No entanto, há que se pensar nas fragilidades impostas ao processo de trabalho docente, o qual tem sido objeto de diversas críticas, que reverberam na formação docente e, sobretudo, nos aspectos didático-pedagógicos. Inserem-se aí, as dicotomias no ensino em saúde, apontadas por vários estudos (teoria-prática, saúde-doença, promoção e cura, básico e profissional, ensino e pesquisa) ${ }^{1,7}$.

Destarte, a questão da docência em saúde assume grande relevância no debate, problematizando-se em torno dos desafios e das dificuldades que ela vem enfrentando na mudança necessária aos processos formativos ${ }^{8}$. A docência em saúde torna-se uma temática importante no momento em que a formação de novos perfis profissionais passam por transformações e inovações curriculares, considerando a prática do professor como eixo estruturante, a qual, segundo Motta e Ribeiro ${ }^{4}$, é entendida como uma prática social complexa e interdisciplinar que exige competências para a ação.

No que diz respeito à formação docente, de modo geral, a Lei de Diretrizes e Bases da Educação Nacional, de 1996, admite que os docentes de nível superior sejam preparados 
pela pós-graduação stricto e lato sensu. A Coordenação de Aperfeiçoamento de Pessoal de Nível Superior (Capes) aponta os mestrados e doutorados acadêmicos como locus de formação docente ao assinalar que estes têm o intuito de promover a formação de professores para o ensino superior ${ }^{9,10}$.

Segundo Ribeiro e Cunha", há uma compreensão de que a qualidade no ensino superior depende da relação de indissociabilidade do ensino com a pesquisa e a extensão; todavia, o lugar da formação para o exercício do magistério superior seria a pós-graduação stricto sensu. Esses autores mencionam que, na esfera da pós-graduação, espaço privilegiado da formação de docentes, há relativo privilégio da formação de pesquisadores, uma vez que eles se constituem espaço para a pesquisa e para o aprofundamento dos saberes específicos do campo da saúde, mas a consolidação dos saberes da prática pedagógica fica em segundo plano.

A partir de uma aproximação inicial à literatura científica sobre a docência em saúde enquanto objeto de estudo, poucos trabalhos foram encontrados. Um estudo de revisão sistemática da literatura sobre a docência em saúde no Brasil, realizado por Araújo et al.12, identificou no total de publicações selecionadas (76) no período de 1997 a 2007 que 43\% delas eram sobre a docência em enfermagem; $33 \%$, sobre a docência em medicina; $9 \%$, em odontologia; e 9\%, sobre a docência nas demais profissões da saúde, as quais contemplam o ensino na graduação, a formação docente e métodos de ensino inovadores como temáticas centrais de interesse. $\mathrm{O}$ estudo evidencia a necessidade de compreensão do processo de mudança na área e aponta para a necessidade de diretrizes para a elaboração de um projeto de desenvolvimento docente.

Diante dos pressupostos, torna-se importante colocar em discussão a produção científica sobre docência em saúde no Brasil, situando-se como condição fundamental para identificar as lacunas do conhecimento. Nesse sentido, este trabalho tem como objetivo analisar a produção científica sobre docência em saúde no Brasil, visando identificar suas características, os principais temas de investigação e as possíveis lacunas do conhecimento.

\section{Metodologia}

Realizou-se um estudo de síntese da produção científica a partir de artigos publicados sobre a temática 'Docência em Saúde'. Foram considerados estudos nacionais, em língua portuguesa, publicados sobre o tema, independentemente do ano de publicação, até o momento de realização da busca (2017), no Scientific Electronic Library Online (SciELO) e na Literatura Latino-Americana e do Caribe em Ciências da Saúde (Lilacs). A escolha por uma revisão da literatura exclusivamente nacional, para o presente estudo, baseia-se no fato de que a docência em saúde no Brasil pode ter recebido forte influência das mudanças ocorridas nas políticas de saúde e, consequentemente, das exigências das políticas de formação profissional para o SUS, passando a envolver questões específicas do sistema público de saúde, considerando-se, portanto, que sua práxis e sua identidade são construídas em um universo sociocultural específico.

Em cada uma das bases (SciELO e Lilacs), foram utilizadas as seguintes palavras de busca: docentes; professores; ensino; docência universitária; formação docente; formação de professores; prática docente; trabalho docente; competências pedagógicas; trajetória docente e identidade docente, cada uma combinada com a palavra saúde, separadamente, com busca em qualquer parte do texto. A análise dos trabalhos foi precedida de uma fase exploratória, em que foram excluídos os capítulos de livros, as normas técnicas, os manuais, as teses e as dissertações, os relatórios técnicos e os documentos institucionais. Trabalhos que não continham resumos também foram eliminados. Em alguns casos, quando se utilizavam diferentes descritores ou bases de dados, ocorria duplicidade de publicações, sendo consideradas apenas uma vez. 
Após a seleção, procedeu-se à análise das informações de cada estudo, realizando-se leitura interpretativa, sistematização e catalogação, a partir de uma planilha em Excel ${ }^{\circledR}$ contendo: ano de publicação, identificação do estudo, palavras-chave, instituição, estado, região, revista de publicação, Qualis Capes, tipo de estudo (ensaios teóricos/ artigos de discussão/opinativos; estudos empíricos; revisões da literatura e relatos de experiência), objetivos, metodologia, resultados, análise e conclusões. Para a identificação das informações referentes à instituição, estado e região do País, considerou-se o autor principal (primeiro autor do estudo). A classificação das publicações segundo Qualis do periódico baseou-se na Classificação do ano de 2014 para área da saúde coletiva. Foi adotado o Qualis da Saúde Coletiva, por se tratar de uma área com muitas interfaces, de natureza interdisciplinar e multiprofissional, no campo da saúde. Quando não houve classificação para algum periódico nesse ano, recorreu-se à classificação no ano de 2013.

Para a análise, recorreu-se aos textos completos dos trabalhos selecionados. Os estudos foram lidos atentamente para que fossem encontrados pontos de convergência entre os assuntos tratados, sendo extraídas/definidas as seguintes categorias temáticas sobre docência em saúde: Formação docente; Identidade docente; Perfil docente; Prática docente: Saúde do docente e Trajetória docente.

Os trabalhos foram analisados considerando o tipo de estudo: ensaios teóricos/artigos de discussão/opinativos; estudos empíricos; revisões da literatura e relatos de experiência. Além disso, foi considerada a metodologia utilizada na produção das informações, especialmente nos desenhos de pesquisa. Procurou-se, ainda, obter uma estimativa do quantitativo de artigos produzidos ano a ano, de acordo com o tema priorizado, sendo esta e outras informações apresentadas em forma de tabela e gráficos, a fim de facilitar o processo de análise.

\section{Resultados e discussão}

A busca de trabalhos sobre a temática em todo o período até o ano 2017 resultou em 8.638 documentos no Lilacs e em 4.164 no SciELO, totalizando 12.802 documentos, dos quais foram selecionados 627 para uma análise preliminar. Após a exclusão das duplicidades e dos trabalhos que não atendiam aos critérios de inclusão deste estudo, foram analisados, na integra, 99 estudos.

Os anos que tiveram maior concentração de publicações sobre a temática foram 2011 e 2016 com, respectivamente, 13,13\%; e 2017 com 11,11\% (gráfico 1).

Gráfico 1. Evolução temporal das publicações nacionais sobre docência em saúde no Brasil, até 2017, Brasil, 2018

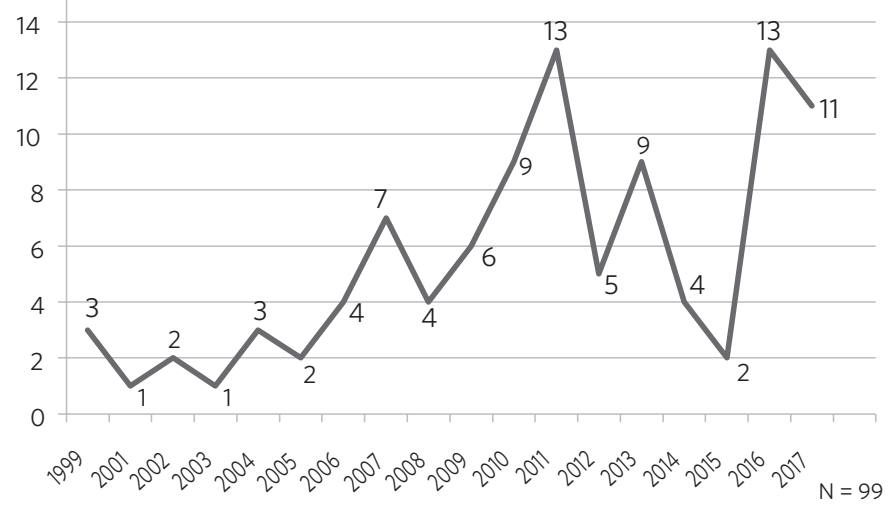


No que se refere às categorias temáticas, nos estudos, houve predominância da Prática docente (36,3\%), seguida de Formação docente (31,3\%), Saúde do docente (18,2\%), Perfil docente (10,1\%), Trajetória docente (3\%) e
Identidade docente (1\%). A distribuição quantitativa por tipo de estudo demonstra que $71,8 \%$ deles são empíricos, $13 \%$ são ensaios teóricos, $10,1 \%$ são relatos de experiência e $5 \%$ são revisões da literatura (tabela 1).

Tabela 1. Distribuição da produção científica sobre docência em saúde, por número de estudos e percentual, segundo categorias analíticas e tipos de estudo, Brasil, 2018

\begin{tabular}{|c|c|c|c|c|c|}
\hline \multirow{2}{*}{\multicolumn{2}{|c|}{ CATEGORIAS / N (\%) }} & \multirow[b]{2}{*}{ Estudo Empírico } & \multirow[b]{2}{*}{ Ensaio Teórico } & \multicolumn{2}{|c|}{ TIPOS DE ESTUDO / N (\%) } \\
\hline & & & & Revisão da Literatura & Relato de Experiência \\
\hline Prática docente & $36(36,36)$ & $28(77,77)$ & $6(15,78)$ & - & $2(5,55)$ \\
\hline Formação docente & $31(31,31)$ & $16(51,61)$ & $6(19,35)$ & $2(6,45)$ & $7(22,58)$ \\
\hline Perfil docente & $10(10,10)$ & $9(90)$ & - & - & $1(10)$ \\
\hline Trajetória docente & $3(3,03)$ & $3(100)$ & - & - & - \\
\hline $\begin{array}{l}\text { Identidade do- } \\
\text { cente }\end{array}$ & $1(1,01)$ & - & $1(100)$ & - & - \\
\hline Saúde do docente & $18(18,18)$ & $15(83,33)$ & - & $3(16,66)$ & - \\
\hline Total & $99(100)$ & $71(71,71)$ & $13(13,13)$ & $5(5,05)$ & $10(10,10)$ \\
\hline
\end{tabular}

A região Sudeste foi a que apresentou maior concentração $(55,55 \%)$, seguida da região Sul (18,18\%) e da região Nordeste (17,17\%). Esses resultados podem ser justificados por maior concentração de instituições de ensino e pesquisa na região Sudeste (gráfico 2). Esses achados revelam que essa região mantém a maior concentração de estudos quando comparados com os resultados do estudo de revisão da literatura de Araújo et al. ${ }^{22}$, o qual analisou a produção científica no período de 1997 a 2007 e identificou que a região Sudeste possui maior concentração dos estudos (67,5\%), além da pouca diferença no quantitativo da produção entre as regiões Sul e Nordeste.

Gráfico 2. Distribuição da concentração da produção científica sobre docência em saúde, por regiões, Brasil, 2018

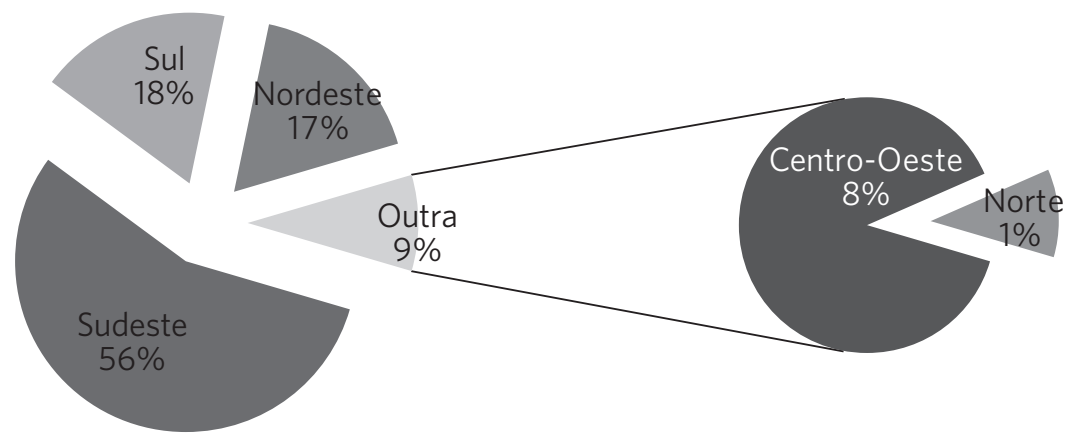

$N=99(100 \%)$ 
No que se refere aos estratos Qualis Capes para a área da Saúde Coletiva, a maioria das publicações selecionadas é B1 (35,35\%), seguido de B2 (26,26\%), B3 (9,09\%), B4 (10,10\%), B5 $(4,04 \%)$ e A2 (2,02\%). Ressaltam-se aspectos qualitativos dessa produção científica, visto que a maioria dos estudos vem sendo publicada em revistas com índices de qualidade elevados (gráfico 3).

Gráfico 3. Distribuição da produção científica sobre docência em saúde, segundo Qualis Capes na área da saúde coletiva, 2012-2014, Brasil, 2018

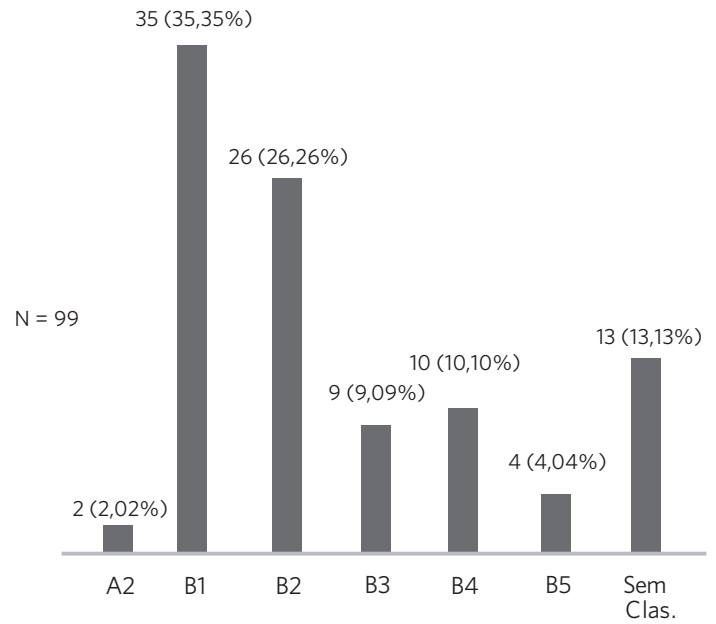

\section{Categorias analíticas}

\section{PRÁTICA DOCENTE}

Compostas por 36 trabalhos, publicados no período entre 2004 e 2017, produções sobre prática docente são, em sua maioria, de natureza empírica $(77,77 \%)$, seguidas por manuscritos teóricos $(16,66 \%)$ e por relatos de experiência $(5,55 \%)$. No que se refere à distribuição geográfica, os estudos são oriundos de diferentes regiões do País: Sudeste (44,44\%), Sul $(22,22 \%)$, Nordeste $(22,22 \%)$ e Centro-Oeste $(11,11 \%)$, publicados em revistas científicas com Qualis que variam de B5 a A2.

Essa categoria engloba trabalhos com as seguintes abordagens: Gestão da docência; Concepções, características e propostas do trabalho docente; Trabalho em equipe entre docentes; Prática docente em cursos específicos; Percepções sobe a parceria ensino-serviço;
Concepções sobre a prática pedagógica; Inovação na prática pedagógica; Avaliação da prática docente; Metodologia do ensino-aprendizagem; Desafios da prática docente.

Os artigos selecionados possuem os objetivos mais variados, a saber: analisar questões relativas à gestão coletiva da atividade docente; investigar os saberes docentes que alicerçam a prática pedagógica dos professores; compreender as concepções dos docentes sobre cuidado integral em saúde e sobre o ensino de graduação extramuros, entre outros. As metodologias utilizadas são, em sua maioria, qualitativas, envolvendo aplicação de questionários e entrevistas semiestruturadas.

Quando analisados os estudos sobre prática docente por área profissional, identifica-se que, dos 36 estudos, 14 deles (38,88\%) são na área de enfermagem, seguida de medicina com 4 estudos (11,11\%), de odontologia com 3 $(8,33 \%)$ e de fonoaudiologia e educação física (ambas com 2,77\% cada). Esses estudos trazem, 
de modo geral, a problemática das demandas sociais e os feitos produzidos pelas novas diretrizes curriculares dos cursos de saúde que colocam desafios à prática docente nas instituições de educação superior. Nesse sentido, os princípios do SUS e as políticas de saúde são apontadas nos estudos como norteadores dos processos de mudanças, na formação profissional em saúde ${ }^{13-23}$. Já o estudo de Rozendo ${ }^{24}$ busca caracterizar as práticas docentes - em nível de planejamento, execução e avaliação de atividades e de ensino-aprendizagem - utilizadas por professores dos cursos de Odontologia, Medicina, Enfermagem, Farmácia, Psicologia, Nutrição, Serviço Social e Medicina Veterinária no Brasil. O destaque para o maior quantitativo de trabalhos publicados sobre docência na área de Enfermagem também foi revelado pelo estudo de Araújo et al. ${ }^{\mathbf{1 2}}$, no qual a Enfermagem apareceu com $43,42 \%$ do total de publicações analisadas no período de 1997 a 2007.

Nessa perspectiva, são colocados os desafios para a integração ensino-serviço e a adoção de novas abordagens metodológicas e de ensino-aprendizagem estimuladas pelo Programa de Reorientação da Formação dos Profissionais em Saúde (Pró-Saúde) ${ }^{19}$. Esses desafios evidenciam as fragilidades da formação docente no Brasil - entre as quais, o pouco preparo pedagógico do docente - diante das exigências da educação contemporânea, que, por sua vez, possui relação direta com as transformações no mundo do trabalho em saúde.

Os estudos classificados na categoria Prática docente são, em sua maioria, de abordagem qualitativa. O estudo de Araújo et al. ${ }^{25}$ discute acerca das abordagens pedagógicas propostas na classificação de Libâneo e sua utilização no processo de formação de força de trabalho na enfermagem. Utilizando categorias relacionadas com o modelo de Meleis, o estudo de Diniz e Avelar ${ }^{\mathbf{1 8}}$ discute princípios e práxis dos docentes ante uma atitude crítico-reflexiva voltada ao processo de ensino. A teoria da comunicação de Habermas também é utilizada por Ribeiro ${ }^{26}$ como referência para um trabalho sobre currículo e docência, o qual oferece como resultados indicadores metodológicos que permitem transformar a prática docente em um processo permanente de construção do conhecimento. Para Pereira e Chaoucha ${ }^{17}$, as práticas pedagógicas precisam ocupar um novo lugar no ensino superior, que ainda está muito voltado à valorização e produção de conhecimentos.

Os estudos concluem que há fragilidades na apropriação teórica e pedagógica que possam efetivar mudanças no processo ensino-aprendizagem e apontam para a necessidade de rever tanto a formação quanto a atualização didático-pedagógica do professor universitário para que se possa buscar uma formação generalista, humanista, crítica e reflexiva no campo da saúde. Dentre as fragilidades, destacam-se a desvalorização das atividades de ensino e a supervalorização da pesquisa e produção científica, a falta de uma identidade profissional docente e a resistência a mudanças e incorporação de inovações pedagógicas, sinalizando pontos de conflito em relação a paradigmas que se articulam diretamente a questões curriculares e político-estruturais.

Alguns estudos evidenciam que, na prática docente, há predominância da educação 'bancária', segundo aspectos conceituais de Paulo Freire, caracterizando-se pela ênfase no tradicionalismo, na transmissão do conhecimento, excesso de carga horária com integração curricular14,24,27,28.

\section{FORMAC̣ÃO DOCENTE}

Essa categoria é composta por 31 trabalhos, publicados entre os anos de 2004 e 2017, em revistas que vão do Qualis B5 ao A2. Os estudos são majoritariamente do tipo empírico (51,61\%), seguidos pelos relatos de experiência (22,58\%), pelos trabalhos teóricos (19,35\%) e pelas revisões de literatura (6,45\%). Os artigos são provenientes, em sua maioria, do estado de São Paulo (48,38\%).

Os trabalhos selecionados podem ser sistematizados nas seguintes subcategorias: Formação pedagógica na pós-graduação ${ }^{9,29-32}$; 
Estágio em docência ${ }^{33-36}$; Formação pedagógica do Enfermeiro docente ${ }^{37-41}$; Formação pedagógica do Nutricionista docente $\mathbf{4 2 , 4 3}^{\mathbf{4}}$ Formação pedagógica do Odontólogo docente 28,44; Formação pedagógica do fonoaudiólogo docente ${ }^{45}$; Formação docente em Educação a Distância (EAD) ${ }^{\mathbf{4 6}-49}$; Tecnologia Educacional na formação docente; Tecnologia da Informação e Comunicação na formação docente50; Avaliação da formação docente ${ }^{51}$. No conjunto de 31 estudos sobre formação docente, quando analisados por área profissional, identifica-se que $29,03 \%$ são na área de enfermagem, seguida de nutrição e de odontologia, ambas com $6,45 \%$ cada, e de fonoaudiologia com $3,22 \%$ (um estudo).

Os estudos dessa categoria possuem objetivos diversos, que vão desde a reflexão sobre o processo de formação docente, as concepções e as práticas sobre aspectos didático-pedagógicos de pós-graduando, de forma ampla, até a análise da formação pedagógica para a docência na graduação na área da saúde.

Em sua maioria, de abordagem qualitativa, os estudos não explicitam em suas respectivas metodologias quais referenciais teóricos conceituais foram utilizados, revelando a pouca importância dada aos referenciais do campo da educação, os quais poderiam trazer possibilidades de problematização das lacunas existentes na formação docente que, consequentemente, refletem na prática pedagógica. A teoria dos campos de Pierre Bourdieu e a teoria do currículo de Tomaz Tadeu da Silva foram utilizadas por Corrêa e Ribeiro ${ }^{32}$ para analisar a formação docente na pós-graduação em Saúde Coletiva.

É possível identificar que a pós-graduação não toma a questão da formação pedagógica como objeto de interesse. Segundo Corrêa e Ribeiro ${ }^{31}$, em seu estudo sobre a relevância e a necessidade da formação pedagógica do professor universitário no espaço da saúde coletiva, verificou-se que os mestrados e doutorados apresentam uma tendência à formação técnica-instrumental. Esses achados corroboram os resultados da pesquisa de Figueredo et al.9, a qual analisou a formação didático-pedagógica na pós-graduação stricto sensu em Ciências da Saúde nas universidades federais do Nordeste, constatando que a distribuição dos componentes curriculares que correspondem à formação didático-pedagógica se apresentou de forma optativa em detrimento das obrigatórias, além disso, desvinculadas da discussão entre teoria, epistemologia da educação e prática docente, mostrando-se insuficientes nos currículos da pós-graduação. Para Batista7(290-291):

Os contextos em que se desenvolvem as propostas de formação didático-pedagógica na área da saúde contêm singularidades que devem ser compreendidas e discutidas: o domínio do conteúdo e o sucesso da prática profissional são, comumente, considerados suficientes para o exercício da docência; a valorização da formação docente no contexto da pós-graduação brasileira é posta em segundo plano em relação à formação do pesquisador; há uma certa desarticulação entre as áreas da saúde e da educação na sociedade em geral e, particularmente, no espaço acadêmico, alimentando uma disputa em torno da responsabilidade de formar o professor.

Ainda, é possível verificar que: a educação permanente do processo de formação docente parece ser uma demanda crescente; o estágio de docência na formação da pós-graduação é relevante na formação dos futuros docentes; há necessidade de desenvolver uma cultura de valorização do ensino na universidade e na pós-graduação. A complexidade da prática pedagógica deve ser assumida em todas as suas dimensões, reconhecendo a docência como uma prática que exige formação específica, caracterizada por elementos complexos que vão além do domínio de determinado conteúdo, não a reduzindo somente à instrumentação técnica, mas, fundamentalmente, uma reflexão crítica sobre esta prática e a realidade em que se processa.

Nessa perspectiva, os estudos apontam para a necessidade de um projeto de 
desenvolvimento docente na área da saúde. Segundo Batista ${ }^{7}$, o desenvolvimento docente é uma temática de grande importância, haja vista que a graduação dos cursos da área da saúde passa por transformações curriculares e metodológicas, incluindo a integração curricular, o currículo centrado na comunidade, a implementação de inovações educacionais, a aprendizagem baseada em problemas, entre outras que têm sido implementadas e avaliadas.

\section{PERFIL, TRAJETÓRIA E IDENTIDADE DOCENTE}

Composta por 10 artigos, a categoria Perfil docente apresenta trabalhos, em sua maioria, do estado de São Paulo (50\%), seguidos pelos estados da Bahia, de Minas Gerais, de Alagoas, do Rio de Janeiro e do Rio Grande do Sul (com $10 \%$ cada estado). Publicados em revistas com o Qualis que vão do B3 ao B1, os artigos são predominantemente empíricos (90\%). Há ainda um relato de experiência (10\%).

As metodologias adotadas são qualitativas, envolvendo métodos descritivos, exploratórios, analíticos ou típicos da pesquisa-ação. Destaca-se, nessa categoria, a quantidade de artigos destinados a analisar o perfil dos docentes de enfermagem (3)52-54, apesar de a maioria dos estudos se dedicarem a analisar o perfil geral dos docentes da área da saúde. De modo geral, os estudos apontam para a necessidade de formação de um perfil docente, que possa dar conta das exigências impostas pela educação do profissional de saúde na contemporaneidade, sem perder de vista as necessidades sociais e as transformações no mundo do trabalho.

Já a categoria Trajetória docente é composta por três trabalhos ${ }^{55-57}$, provenientes de Universidades Públicas Estaduais e Federais. Os estudos foram publicados em 2003 (Universidade do Estado do Rio de Janeiro Uerj), em 2010 (Universidade Estadual de Feira de Santana - UEFS) e em 2017 (Universidade Federal de São Carlos - UFSCar), nas revistas 'Physis' e 'Interface', ambas com Qualis B1. Entre as fundamentações teóricas dos trabalhos, destacamos as contribuições de Bourdieu, Sousa Santos, Anastasiou e Pimenta nos trabalhos.

De natureza empírica, os três trabalhos possuem objetos de estudo distintos, mas objetivos semelhantes. Ribeiro ${ }^{55}$ busca analisar as representações de docência e formação pedagógica presentes no Projeto Político-Pedagógico de um Curso de Mestrado em Saúde Coletiva. Os referenciais de Bourdieu, Sousa Santos, Anastasiou, Pimenta, Cunha e Lucarelli deram a principal sustentação teórica ao estudo, o qual aponta que, mesmo tendo a docência como expectativa de ação profissional, pouco encontra nas propostas curriculares essa dimensão, havendo discrepância entre as suas motivações e a proposta de formação, o que pode indicar a fragilidade do campo científico da educação e da pedagogia universitária nesse contexto.

O estudo de Bulcão ${ }^{56}$ utilizou o referencial da sociologia das profissões com o objetivo de conhecer o professor médico, no que diz respeito a seus valores e comportamentos profissionais. Já o estudo de Silva ${ }^{57}$ teve como objetivo analisar a trajetória docente e a formação de terapeutas ocupacionais para Atenção Primária à Saúde (APS) no estado de São Paulo.

A categoria Identidade docente é composta por um trabalho, realizado por pesquisadores da Universidade Federal Fluminense (UFF) ${ }^{58}$, publicado na revista 'Interface', com Qualis B1. Trata-se de um estudo teórico, que buscou analisar as relações dos saberes que criam a identidade dos docentes da área da saúde, bem como valorizar o entendimento das relações e posicionamentos sociais que imprimem marcas, no exercício da docência, como elementos que contribuem ou não para a efetivação das propostas de transformação dos processos de formação em saúde em curso, a partir dos condicionantes éticos e políticos do SUS.

\section{SAÚDE DO DOCENTE}

Chama atenção o número de artigos encontrados nessa categoria. Foram 18 artigos, publicados entre 2007 e 2017, sendo os anos de 
2016 e 2017 aqueles com maior quantidade de publicação ( $27,77 \%$ cada). Os trabalhos são provenientes das regiões Sudeste (61,11\%), Sul (16,66\%) e Centro-Oeste (11,11\%), tendo sido publicados em revistas com o Qualis entre $\mathrm{B} 4 \mathrm{e} \mathrm{B} 1$.

Todos os artigos selecionados e pertencentes a essa categoria são do tipo empírico, e, em sua maioria, buscam identificar e analisar entre docentes, da área da saúde, os momentos de insatisfação, desgaste psíquico ou outros indicadores que são relevantes no estudo da saúde mental. Utilizaram-se, para a coleta de dados, questionários, protocolos como o MBI (Maslach Burnout Inventory), Inventário de Sintomas de Stress para Adultos de Lipp, Questionário sobre percepção do próprio stress, entre outros. Observou-se que o quantitativo de trabalhos sobre a saúde do docente enfermeiro (7) corresponde a aproximadamente $39 \%$ dos estudos classificados nessa categoria ${ }^{59-65}$.

Os estudos selecionados apontam que os principais fatores que afetam a saúde mental são questões éticas, excesso de atividades da carreira acadêmica e dificuldades no ambiente de trabalho. As esferas pessoais, sociais e institucionais devem atuar conjuntamente para atender às complexas necessidades desse profissional66-68. Os estudos reafirmam que a sobrecarga de trabalho do professor é recorrente, reduzindo assim a sua disponibilidade de tempo para atividades de interesse pessoal, o que afeta sua qualidade de vida. Além disso, confirmou-se o imperativo da resistência coletiva organizada de maneira a modificar o quadro de precarização do trabalho do professor.

Souza et al. ${ }^{68}$ analisaram em seu estudo a nova organização do trabalho dos professores universitários e sua relação com a saúde desses profissionais, partindo do pressuposto que a precarização do trabalho nas universidades públicas vem gerando repercussões na saúde dos docentes da educação superior. Somam-se a esse contexto, as fortes pressões organizacionais tendo como consequência a intensificação do trabalho e o aumento da exigência de produtividade acadêmica.
Por sua vez, o estudo de Silvério et al.69 sobre ensino na área da saúde e sua repercussão na qualidade de vida docente revela que diferentes fatores promovem ou limitam a qualidade de vida do docente, os quais estão relacionados com a dinâmica das diversas interações pessoais desenvolvidas nos contextos dos processos de ensino-aprendizagem, especialmente naqueles em que há atividades que envolvem os serviços de saúde e a população.

\section{Considerações finais}

O estudo possibilitou o acompanhamento da tendência da produção científica sobre docência em saúde no Brasil. Nesse sentido, foi possível identificar as categorias temáticas com maior número de estudos, as que despontaram com número significativo de trabalhos e aquelas que apontam a necessidade de aprofundamentos em questões que se constituem em lacunas de conhecimento. Enquanto categorias como Prática docente e Formação docente praticamente dividem a totalidade dos trabalhos produzidos, seguidas da categoria Saúde do docente, os grupos, Perfil docente, Trajetória docente e Identidade docente apresentam número reduzido de publicações. Os estudos revelam a complexidade da prática pedagógica e reafirmam a necessidade da formação docente no campo da saúde.

O debate sobre docência universitária e a necessidade de introduzir novas metodologias de aprendizagem vêm desafiando pesquisadores, educadores e instituições para formulação e implementação de ações concretas que promovam mudanças na formação dos perfis profissionais que favoreçam as transformações das práticas e nas relações das equipes e trabalhadores de saúde.

Embora vários estudos tenham apresentado a problemática da formação docente na pós-graduação, na literatura científica, ainda nos restam questões que se constituem como lacunas do conhecimento, a exemplo da abordagem sobre a pedagogia 
universitária na docência em saúde e sobre a forma como os programas de pós-graduação devem formar pedagogicamente. Nesse sentido, há carência de estudos mais aprofundados sobre a estrutura curricular da pós-graduação stricto sensu e sobre os aspectos da formação didático-pedagógica nesse espaço.

O investimento em temáticas que envolvam a formação dos trabalhadores do SUS em muito contribuirão para a organização das políticas e práticas de educação no setor saúde, ampliando formatos e conteúdos que abriguem as novas interrelações que favorecem os perfis necessários à atualidade.

\section{Colaboradores}

Silva VO (0000-0003-4149-1777)* contribuiu para a concepção, o planejamento, a análise e a interpretação dos dados; revisão crítica do conteúdo; e aprovação da versão final do manuscrito. Pinto ICM (0000-0002-1636-2909)* contribuiu para a revisão crítica do conteúdo e a aprovação da versão final.

\section{Referências}

1. Maia JA. O currículo no ensino superior e saúde. In: Batista NA, Batista SH. Docência em Saúde: temas e experiências. São Paulo: Senac; 2004.

2. Batista NA, Batista SH. Docência Universitária em Saúde, Formação e Interdisciplinaridade. In: Batista NA, Batista SH, Abdala IG. Ensino em Saúde: visitando conceitos e experiências. São Paulo: Arte \& Ciência; 2005.

3. Pimenta SG, Anastasiou LGC. Docência no ensino superior. 2. ed. São Paulo: Cortez; 2003.

4. Motta IJ, Ribeiro VMB. Quem educa queer: a perspectiva de uma analítica queer aos processos de educação em saúde. Ciênc. Saúde Colet. 2013; 18(6):1695-1704.

*Orcid (Open Researcher and Contributor ID).
5. Souza KR, Mendonça ALO, Rodrigues MAS, et al. A nova organização do trabalho na universidade pública: consequências coletivas da precarização na saúde dos docentes. Ciênc. Saúde Colet. 2017; 22(11):3667-3676.

6. Catani AM, Oliveira JF, Michelotto RM. As políticas de expansão da educação superior no Brasil e a produção do conhecimento. Fundam. humanid. 2007; 1(23):47-64.

7. Batista NA. Desenvolvimento docente na área da saúde: uma análise. Trab. educ. saúde. 2005; 3(2):283-294.

8. Pinto ICM, coordenadora. Oficina sobre formação docente em Saúde Coletiva. In: Associação Brasileira de Saúde Coletiva. GT Trabalho e Educação [Relatório]. 2012 Maio 7-8; Rio de janeiro: Escola Nacional de Saúde Pública (Ensp/Fiocruz), 2012. p. 1-12.

9. Figueredo WN, Laitano ADC, Santos VPFA, et al. Formação didático-pedagógica na pós-graduação 
stricto sensu em Ciências da Saúde nas Universidades Federais do Nordeste do Brasil. Acta paul. enferm. 2017; 30(5):497-503.

10. Barbosa ECV, Viana LO. Um olhar sobre a formação do enfermeiro/docente no Brasil. Rev. Enferm. UERJ. 2008; 16(3):339-344.

11. Ribeiro ML, Cunha MI. Trajetórias da docência universitária em um programa de pós-graduação em Saúde Coletiva. Interface (Botucatu). 2010; 14(32):52-68.

12. Araujo EC, Batista SH, Gerab IF. A produção científica sobre docência em saúde: um estudo em periódicos nacionais. Rev. bras. educ. med. 2011; 35(4):486-492.

13. Madeira MZA, Lima MGSB. A prática pedagógica das professoras de enfermagem e os saberes. Rev. bras. Enferm. 2007; 60(4):400-404.

14. Freitas DA, Santos EMS, Lima LVS, et al. Saberes docentes sobre processo ensino-aprendizagem e sua importância para a formação profissional em saúde. Interface comun. saúde educ. 2016; 20(57):437-448

15. Andrade SR, Boehs AE, Boehs CGE. Percepções de enfermeiros docentes e assistenciais sobre a parceria ensino-serviço em unidades básicas de saúde. Interface (Botucatu). 2015; 19(54):537-547.

16. Guimarães GL, Viana LO. O valor social no ensino da enfermagem. Esc. Anna Nery Rev. Enferm. 2012; 16(3):508-513

17. Pereira WR, Chaoucha SH. Identificação de novas práticas pedagógicas na percepção dos docentes de um curso de enfermagem. Ciênc. cuid. Saúde. 2010; 9(1):99-106.

18. Diniz SN, Avelar MCQ. A prática docente de enfermeiros de instituições de saúde numa universidade privada. Ciênc. cuid. Saúde. 2009; 8(2):176-183.

19. Forte FDS, Vieira LB, Pessoa TRRF, et al. Portfólio: desafio de portar mais que folhas: a visão do docente de odontologia. Rev. bras. educ. med. 2012; 36(1) (supl2):25-32.

20. Turini B, Almeida MJ. Os professores de Medicina e o ensino de graduação extramuros. Rev. bras. educ. méd. 2002; 26(3):151-161.

21. Pontes AL, Rego S, Silva Junior AG. Saber e prática docente na transformação do ensino médico. Rev. bras. educ. med. 2006; 30(2):66-75.

22. Moura D, Arce VAR. Atenção primária à saúde: concepções e práticas de docentes fonoaudiólogos. Distúrb. Comum. 2016; 28(1):130-141.

23. Machado RB. Políticas de inclusão e a docência em educação física: uma reflexão sobre as práticas. Rev. bras. ciênc. Esporte. 2017; 39(3):261-267.

24. Rozendo CA, Casagrande LDR, Schneider JF, et al. Uma análise das práticas docentes de professores universitários da área de saúde. Rev. latinoam. Enferm. 1999; 7(2):15-23.

25. Araújo DV, Silva CC, Silva ATMC. Formação de força de trabalho em saúde: contribuição para a prática educativa em enfermagem. Cogitare enferm. 2008; 13(1):10-17.

26. Ribeiro VMB. Uma pequena conversa sobre currículo, prática docente e teoria da ação comunicativa. Physis. 1999; 9(2):99-116.

27. Costa NMSC. Docência no ensino médico: por que é tão difícil mudar? Rev. bras. educ. med. 2007; 31(1):21-30.

28. Secco LG, Pereira MLT. Concepções de qualidade de ensino dos coordenadores de graduação: uma análise dos cursos de odontologia do Estado de São Paulo. Interface (Botucatu). 2004; 8(15):313-330.

29. Freitas MAO, Seiffert OMLB. Formação docente e o ensino de Pós-Graduação em Saúde: uma experiência na UNIFESP. Rev. bras. enferm. 2007; 60(6):635-640.

30. Ponce de Leon CGRM, Silva CC. Formação de formadores: a prática educativa de um programa de pós-graduação em enfermagem. Rev. bras. enferm. 
2006; 59(5):636-641.

31. Corrêa GT, Ribeiro VMB. Formação pedagógica na pós-graduação stricto sensu em saúde coletiva. Ciênc. Saúde Colet. 2013; 18(6):1647-1656.

32. Abensur PLD, Carvalho GPM, Ruiz ML. O processo de formação didático pedagógica em saúde: aprendizagens percebidas na voz dos pós-graduandos. ABCS health sci. 2016; 40(3):158-163.

33. Siniak DS, Silva AB, Pinho LB. Relato de experiência de estágio de docência na área de enfermagem psiquiátrica e saúde mental. Ciênc. cuid. Saúde. 2013; 12(3):593-598.

34. Tomaz APKA, Tocantins FR, Souza SR. Estágio docência realizado num hospital universitário do estado do Rio de Janeiro - relato de experiência. Rev. pesqui. cuid. fundam. 2014; 6(2):856-862.

35. Mielke FB, Olschowsky A. A experiência do estágio de docência. Cogitare enferm. 2009; 14(3):579-583.

36. Pinho LB, Santos SMA. Estágio de docência em enfermagem psiquiátrica: uma experiência durante a pós-graduação. Rev. gaúch. Enferm. 2006; 27(2):176-184.

37. Pimentel V, Mota DDCF, Kimura M. Reflexões sobre o preparo para a docência na pós-graduação em enfermagem. Rev. esc. enferm. USP. 2007; 41(1):161-164.

38. Rodrigues MTP, Mendes Sobrinho JAC. Enfermeiro professor: um diálogo com a formação pedagógica. Rev. bras. enferm. 2007; 60(4):456-459.

39. Maftum MA, Alencastre MB. Cenário da qualificação docente de enfermagem em saúde mental no Paraná. Nursing. 2008; 11(124):404-410.

40. Barbosa ECV, Viana LO. Um olhar sobre a formação do enfermeiro/docente no Brasil. Rev. enferm. UERJ. 2008; 16(3):339-344.

41. Backes VMS, Menegaz JC, Miranda FAC, et al. Lee shulman: contribuições para a investigação da formação docente em enfermagem e saúde. Texto \& contexto enferm. 2017; 26(4):e1080017.

42. Costa NMSC. Formação pedagógica de professores de nutrição: uma omissão consentida? Rev. Nutr. 2009; 22(1):97-104

43. Cardoso CGLV, Silva AS, Vargas GJ, et al. O papel dos docentes na formação de novos professores de nutrição. Rev. bras. educ. med. 2014; 38(3):367-371.

44. Baltazar MMM, Moysés SJ, Bastos CCBC. Profissão, docente de odontologia: o desafio da pós-graduação na formação de professores. Trab. educ. saúde. 2010; 8(2):285-303.

45. Nardi V, Cardoso C, Araújo RPC. Formação acadêmico-profissional dos docentes fonoaudiólogos do estado da Bahia. Rev. CEFAC. 2012; 14(6):1122-1138.

46. Ruiz-Moreno L, Leite MTM, Ajzen C. Formação didático-pedagógica em saúde: habilidades cognitivas desenvolvidas pelos pós-graduandos no ambiente virtual de aprendizagem. Ciênc. educ. (Bauru). 2013; 19(1):217-229.

47. Paim MC, Guimarães JMM. Importância da formação de docentes em EAD no processo de educação permanente para trabalhadores do SUS na Bahia. Rev. baiana saúde pública. 2009; 33(1):94-103.

48. Mezzari A. O uso da Aprendizagem Baseada em Problemas (ABP) como reforço ao ensino presencial utilizando o ambiente de aprendizagem Moodle. Rev. bras. educ. med. 2011; 35(1):114-121.

49. Ruiz-Moreno L, Sonzogno MC. Formação pedagógica na pós-graduação em saúde no ambiente Moodle: um compromisso social. Pro-Posições. 2011; 22(3):149-164.

50. Abensur SI, Tamosauskas MRG. Tecnologia da informação e comunicação na formação docente em Saúde: relato de experiência. Rev. bras. educ. med. 2011; 35(1):102-107.

51. Bomfim MI, Goulart VMP, Oliveira LZ. Formação docente na área da saúde: avaliação, questões e tensões. Interface (Botucatu). 2014; 18(51):749-758. 
52. Backes DSS, Marinho M, Costenaro RS, et al. Repensando o ser enfermeiro docente na perspectiva do pensamento complexo. Rev. bras. enferm. 2010; 63(3):421-426.

53. Contim D, Sanna MC. Ensino de administração de serviços de saúde: perfil de enfermeiras que exerceram a docência. Acta paul. enferm. 2011; 24(6):756-761.

54. Terra FS, Secco IAO, Robazzi MLCC. Perfil dos docentes de cursos de graduação em enfermagem de universidades públicas e privadas. Rev. enferm. UERJ. 2011; 19(1):26-33.

55. Ribeiro ML, Cunha MI. Trajetórias da docência universitária em um programa de pós-graduação em Saúde Coletiva. Interface (Botucatu). 2010; 14(32):52-68.

56. Bulcao LG, Sayd JD. As razões da escola médica: sobre professores e seus valores. Os valores dos médicos e os impasses da escola médica. Physis. 2003; 13(1):11-38.

57. Silva RAS, Oliver FC. Trajetória docente e a formação de terapeutas ocupacionais para atenção primária à saúde. Interface (Botucatu). 2017; 21(62):661-673.

58. Oliveira GS, Koifman L. Uma reflexão sobre os múltiplos sentidos da docência em saúde. Interface (Botucatu). 2013; 17(44):211-218.

59. Corral-Mulato S, Bueno SMV, Franco DM. Docência em Enfermagem: insatisfações e indicadores desfavoráveis. Acta paul. enferm. 2010; 23(6):769-774.

60. Santos I, Cavalcante LB, Berardinelli LMM. Estudo sobre hábitos de vida de docentes de enfermagem segundo os modos adaptativos de Roy. Rev. enferm. UERJ. 2010; 18(1):48-54.

61. Carbogim FC, Gonçalves AMC. Docentes de enfermagem: prazer e sofrimento no trabalho. REME rev. min. Enferm. 2007; 11(3):291-296.
62. Soares RJO, Zeitoune RCG, Lisboa MTL, et al. Fatores facilitadores e impeditivos no cuidar de si para docentes de enfermagem. Texto contexto - enferm. 2011; 20(4):758-765.

63. Terra FS, Marziale MHP, Robazzi MLCC. Evaluation of Self-esteem in Nursing Teachers at Public and Private Universities. Rev. Latino-Am. Enfermagem. 2013; 21(spe):71-78.

64. Barlem ELD, Lunardi VL. Satisfação e sofrimento no trabalho do enfermeiro docente: uma revisão integrativa. REME rev. min. Enferm. 2016; 20(e939):1-8.

65. D'Oliveira CAFB, Almeida CM, Souza NVDO, et al. Prazer e sofrimento no trabalho: perspectivas de docentes de enfermagem. Rev. baiana enferm. 2017; 31(3):e20297.

66. Gomes KK, Sanchez HM, Sanchez EGM, et al. Qualidade de vida e qualidade de vida no trabalho em docentes da saúde de uma instituição de ensino superior. Rev. bras. med. Trab. 2017; 15(1):18-28.

67. Leite AF, Nogueira JAD. Fatores condicionantes de saúde relacionados ao trabalho de professores universitários da área da saúde: uma revisão integrativa. Rev. bras. saúde ocup. 2017; 42(e6):1-15.

68. Souza KR, Mendonça ALO, Rodrigues MAS, et al. A nova organização do trabalho na universidade pública: consequências coletivas da precarização na saúde dos docentes. Ciênc. Saúde Colet. 2017; 22(11):3667-3676.

69. Silvério MR, Patrício ZM, Brodbeck IM, et al. O ensino na área da saúde e sua repercussão na qualidade de vida docente. Rev. bras. educ. méd. 2010; 34(1):65-73.

Recebido em 05/12/2018

Aprovado em 18/04/2019

Conflito de interesses: inexistente

Suporte financeiro: não houve 